\title{
Behavioral Profile of CCK2 Receptor- deficient Mice
}

\author{
Valérie Daugé, Ph.D., Angélique Sebret, Françoise Beslot, Toshimitsu Matsui, M.D., Ph.D., \\ and Bernard P. Roques, Ph.D.
}

CCK2 receptor-deficient mice were used to investigate in vivo the role of this receptor in behavior. Mutant mice showed a neuromuscular impairment in the traction and rotarod tests but not in the chimney test. Brain cholecystokinin has been shown to participate in stress-related behaviors. However, CCK2 receptor-deficient mice did not show behavioral modifications compared to wild-type mice in the elevated plus maze and in the motility conditioned suppression test, indicating that compensatory mechanisms very likely occur following CCK2 receptor invalidation. On the other hand, a hyperlocomotor activity was observed in actimeter which can

KEY WORDS: CCK2 receptor-deficient mice; Memory; Anxiety; Motor activity; Neuromuscular deficits

The cholecystokinin (CCK) neuropeptide has been identified in the brain (Vanderhaeghen 1975; Dockray 1976), the most abundant form corresponding to the C-terminal sulfated octapeptide fragment (CCK8). This neuropeptide interacts with the same affinity with two receptor types, designated CCK1 (previously named

From the Département de Pharmacochimie Moléculaire et Structurale INSERM U266-CNRS UMR 8600, UFR des Sciences Pharmaceutiques et Biologiques, Paris, France (VD, AS, FB, BPR), and Third Division Department of Medicine, Kobe University School of Medicine, Kobe, Japan (TM).

Address correspondence to: Dr. Valérie Daugé, Département de Pharmacochimie Moléculaire et Structurale, INSERM U266-CNRS UMR 8600, UFR des Sciences Pharmaceutiques et Biologiques, 4, avenue de l'Observatoire, 75270 Paris Cedex 06, France. Tel.: (33)-1-53-7395-75, Fax: (33)-1-43-26-69-18, e-mail: dauge@pharmacie. univ-paris5.fr

Received March 29, 2000; revised April 19, 2001; accepted April 30, 2001.

Online publication: 5/21/01 at www.acnp.org/citations/Npp 052101123. be related to an impairment in environmental habituation. Finally, CCK2 receptor-deficient mice showed an impairment of performance in the spontaneous alternation behavior as expected from the opposite effects evoked by CCK2 agonists, supporting the physiological role of CCK2 receptors in attention and/or memory processes. This result is reinforced by the defects observed in these functions after the administration of CCK2 antagonists.

[Neuropsychopharmacology 25:690-698, 2001] (C) 2001 American College of Neuropsychopharmacology. Published by Elsevier Science Inc.

CCK-A) and CCK2 (previously named CCK-B) (Noble et al. 1999) receptors, which both belong to the G-coupled receptor superfamily (Wank et al. 1992; Lee et al. 1993). However, the distribution of these two receptors is quite different since the CCK1-type is abundant in peripheral organs and in few discrete brain regions (Moran et al. 1986; Hill et al. 1987). In contrast, the CCK2-type is the predominant receptor found in the central nervous system, especially in cortical and limbic structures (Gaudreau et al. 1983; Moran et al. 1986; Pélaprat et al. 1987). On the other hand, the gastrinic receptor localized on stomach parietal cells was shown to be identical to the brain CCK2 receptor (Wank et al. 1992).

Pharmacological data using selective CCK agonists or antagonists have shown that CCK receptors play an important role in anxiety and stress-related behaviors, nociception and memory processes (reviews in: Harro et al. 1993; Crawley and Corwin 1994; Daugé and Roques 1995; Shlik et al. 1997). However, some discrepancies exist in the literature about the type of receptors involved in these responses and the efficiency of some selective compounds. One possible explanation could 
be the differences in recognition of two affinity states for the CCK2 receptor, designated $2 \mathrm{a}$ and $2 \mathrm{~b}$ (Durieux et al. 1986; Harper et al. 1999a,b) which could correspond to different couplings to $G$ proteins of a single receptor, resulting in different intracellular events (Pommier et al. 1999) and subsequently in distinct behavioral responses (Derrien et al. 1994; Léna et al. 1999).

A now currently used approach for analyzing the physiological role of a receptor is to generate, by genetic manipulations, mice invalidated for this receptor (Kieffer 1999).

The behavioral profile of CCK2 receptor-deficient mice generated by gene targeting (Nagata et al. 1996; Miyasaka et al. 1999) was carried out in this work. We demonstrate that their emotional responses are not significantly different from those elicited by wild-type animals. In contrast, a motor hyperactivity, a deficit in some attention and/or memory processes, and a neurological/muscular impairment occurred in genetically modified animals. All these modifications will be discussed in terms of possible direct consequences resulting from CCK2 receptor inactivation and/or from compensatory processes due to this receptor invalidation.

\section{METHODS}

\section{Subjects}

CD1 mice (Charles River, Saint-Aubin les Elbeuf, France) (three months old) and CCK2/gastrin receptor deficientmice (three months old) coming from the original background of 129sv/C57BL/6 mice (Nagata et al. 1996) were used. Breeding and genotype analysis of the latter have been done by Transgenic Alliance (L'Arbresle, France). Male and female mice were used. They were housed (groups of 4-5 mice per cage) in the laboratory at least a week before the experiments, in a temperature (22 \pm $\left.1^{\circ} \mathrm{C}\right)$ and humidity $(50 \% \pm 5 \%)$ controlled environment and had free access to food and water.

All experimental procedures were approved by the local ethical committee.

\section{Behavioral Experiments}

Traction Test (from Courvoisier 1956). This test consists of determining the time taken by mice, suspended by their front paws to a metallic wire strung (diameter 1.5 $\mathrm{mm}$ ) placed horizontally $20 \mathrm{~cm}$ over the floor), to grasp the bar with at least one hind paw. A positive response was scored if mice grasped the bar with at least one hind paw in less than $5 \mathrm{sec}$. Results were expressed as percentage of success. Sixty-seven 129sv/C57BL/ 6 mice (34 wild type $(+/+), 33$ CCK2 receptor-deficient mice $(-/-)$ and twenty CD1 mice were studied in a first experiment. Forty $129 \mathrm{sv} / \mathrm{C} 57 \mathrm{BL} / 6$ mice $(20+/+, 20-/-)$ were used for the experiment with the CCKB antagonist $(\mathrm{L} 365,260)$.
Two groups of $+/+$ and $-/-$ were studied, the control group ( $\mathrm{n}=10$ for each strain) received cyclodextrin $(5 \%)$ and the L365,260 group ( $\mathrm{n}=10$ for each strain) was injected i.p. at the dose of $200 \mu \mathrm{g} / \mathrm{kg}, 45 \mathrm{~min}$ before the test. $1000 \mu \mathrm{g} / \mathrm{kg}$ of L365,260 ( $\mathrm{n}=10$ for each group) or cyclodextrin $(5 \%)(\mathrm{n}=10$ for each group) was injected to $+/+$ and $-/-$ mice 45 min before the test.

Chimney Test (from Boissier et al. 1960). The chimney is constituted of a vertical glass tube (length $30 \mathrm{~cm}$, diameter: 26 or $28 \mathrm{~cm}$ depending on the weight of mice). Mice were put in the tube, the head upside down. The test consisted of determining the time taken by mice to climb back, upside down, up to $25 \mathrm{~cm}$ of height. A positive response was scored if mice passed the delineation corresponding to $25 \mathrm{~cm}$ in less than 30 sec. Mice were tested once. Results were expressed as percentage of success. Forty-eight $129 \mathrm{sv} / \mathrm{C} 57 \mathrm{BL} / 6$ mice $(20+/+, 28-/-)$ were studied.

Rotarod Test (from Dunham and Miya 1957). Mice were placed on a stationary $3 \mathrm{~cm}$ diameter cylinder. The rotarod was switched on to a speed of $10 \mathrm{rpm}$, and mice were timed until they fell from the rotarod (maximum cut off time of $120 \mathrm{sec}$ ). Mice that attained a score of 120 sec were removed from the rotarod and returned to their home cage; mice that fell, restarted for a total of three consecutive trials. Mice that could not remain on the stationary cylinder for three trials scored zero. The first and third trials were used for statistical analysis. The same animals as in the traction test were used. Mice were first tested in the traction test and then in the rotarod test (see above traction test).

Actimeter. Mice were individually placed in a plastic cage $(255 \mathrm{~cm} \times 205 \mathrm{~cm})$ under a light intensity of 5 lux in a sound-attenuated room. The animals' horizontal movements were counted with photocells. The test lasted $60 \mathrm{~min}$. Seventeen $129 \mathrm{sv} / \mathrm{C} 57 \mathrm{BL} / 6$ mice $(8+/+$, $9-/-)$ were studied in the first experiment. Fortyeight $(24+/+, 24-/-)$ were used in the experiment with the selective CCK2 agonist (BC264). Two groups of $+/+$ and $-/-$ mice were studied. The control group ( $n=12$ for each strain) received saline and the BC264 group ( $\mathrm{n}=12$ for each group) was injected i.p. at the dose of $3 \mu \mathrm{g} / \mathrm{kg}$, $30 \mathrm{~min}$ before the test.

Open-field Test. Qualitative analysis of spontaneous activity was performed in an open-field corresponding to a large white rectangular area $(70 \mathrm{~cm}$ wide, $90 \mathrm{~cm}$ long, $60 \mathrm{~cm}$ height) strongly illuminated (500 lux) from the top. Black lines on the floor of this field delineated $10 \times 10 \mathrm{~cm}$ squares. Mice, first placed in a corner of the open-field, were examined for one 6-min period. The latency to move out from the corner and to cross two squares (latency time), the number of squares crossed, rearing, grooming and defecations were recorded by an 
experimenter. Forty one 129sv / C57BL/ 6 mice $(19+/+$, $22-/-$ ) were studied.

Elevated Plus Maze Test. The elevated plus maze (first described by Pellow et al. 1985) was used to evaluate mice emotionality. This is a wooden apparatus consisting of four arms ( $16 \mathrm{~cm}$ long, $5 \mathrm{~cm}$ wide). Two opposite arms are surrounded on three faces by $10 \mathrm{~cm}$ high walls (closed arms), while the two other arms are open (open arms). The maze is raised up to a height of $30 \mathrm{~cm}$ over the floor and illuminated (100 lux) from the top. The behavior was observed by an experimenter on a video-computer placed outside the testing sound-attenuated room. In this test, mice were first placed in the central square facing an open arm, and the total number and duration of entries made in open and closed alleys were recorded during $5 \mathrm{~min}$. Results are expressed as the ratio between the cumulative number of visits or time spent in the open parts of the maze considered as an aversive area and the whole number or duration of visits. Nineteen $129 \mathrm{sv} /$ C57BL/ 6 mice $(10+/+, 9-/-)$ were studied.

Motility Conditioned Suppression Test. The assay was performed as previously described by Kameyama and Nagasaka (1982). Mice were placed in a transparent rectangular cage $(30 \times 26 \times 30 \mathrm{~cm})$ with a metallic grid floor. Animal displacements were measured by drawing 12 squares on the floor for counting. The apparatus was located in an illuminated (100 lux) sound-proof room. On the first day, the mouse was left in the test cage for $6 \mathrm{~min}$ and received electric footshocks $(0.1 \mathrm{~Hz}$, $200 \mathrm{~ms}, 100 \mathrm{~V}$ ) through an isolated stimulator (GL 260T, Société Ravia, Bordeaux, France). Each animal received electric shocks in the range of $1.2-3 \mathrm{~mA}$. On the second day, the mouse was placed in the same cage without receiving electric footshocks and motility changes were tested by counting the number of squares crossed, plus the number of rearings in $6 \mathrm{~min}$; mice belonging to the control group were handled in the same way as those in the conditioned suppression group except that they did not receive electric footshocks on the first day. Forty 129 sv / C57BL / 6 mice (20 $+/+, 20-/-)$ were used.

Spontaneous Alternation. The apparatus consists of a symmetrical wooden $Y$ maze with arms $25 \mathrm{~cm}$ long, $8 \mathrm{~cm}$ wide and $15 \mathrm{~cm}$ high. The apparatus was illuminated from the top (100 lux) and the floor was covered with a small amount of sawdust. The behavior was observed by an experimenter on a video-computer placed outside the testing sound-attenuated room. Mice were put in one arm of the maze and the sequence and number of arm entries were recorded over a period of $10 \mathrm{~min}$. An arm visit was recorded when a mouse moved all four paws into the arm. Scoring of alternations consisted of the evaluation of response sequences, in which entering into the least recently visited arm, was considered an alterna- tion response. The proportion of alternations was computed by dividing the number of alternations by the total number of arm visits. In order to obtain a correct measure of the qualitative aspect of the behavior, a minimum of nine visits was retained to calculate the percentage of spontaneous alternation behaviors. Forty two $129 \mathrm{sv} /$ C57BL/ 6 mice $(20+/+, 22-/-)$ were studied.

Nociceptive Experiments. Pain sensitivity to footshock was assessed by threshold analysis as a control for the procedure requiring footshocks, e.g. the motility conditioned suppression test as previously described by Crawley (1999). A sequence of single footshocks was delivered in the same chamber used for the motility conditioned suppression test as described above, and the mouse was observed for flinching, jumping, running and vocalization. Once these behaviors were observed, the sequence was terminated. The sequence begins with $0.72 \mathrm{~mA}$ and proceeds through $0.84 \mathrm{~mA}, 0.96$ $\mathrm{mA}, 1.08 \mathrm{~mA}$ and $1.2 \mathrm{~mA}$ single footshocks of $200 \mathrm{~ms}$ duration each. Most mice showed behavioral responses to the lower footshock levels and therefore did not receive the higher footshocks. Seventeen 129sv/C57BL/6 mice $(7+/+, 10-/-)$ were studied.

Chemicals. The CCK2 agonist, BC264 : [Boc-Tyr $\left(\mathrm{SO}_{3} \mathrm{H}\right)$-gNle-mGly-Trp-(NMe)Nle-Asp-Phe- $\mathrm{NH}_{2}$ ] (Charpentier et al. 1988) was synthesized in the laboratory as previously described.

The CCK2 antagonist L365,260 : [3R-(+)-N-(2,3-dihydro-1-methyl-2-oxo-5-phenyl-1H-1,4-benzodiazepin-3-yl)$\mathrm{N}^{\prime}$-(3-methyl phenyl) urea] (Bock et al. 1989) was a generous gift from Rhône Poulenc Rorer.

BC264 was dissolved in 0.9\% saline while L365,260 was used in the form of a fine suspension in cyclodextrin $(5 \%)$ (Aldrich).

\section{Statistical Analysis}

Behavioral data were analyzed using 1-way analysis (genotype) of variance or 2-way analysis (genotype, treatment) of variance (ANOVA). If the 2-way analysis reached significance, a 1-way analysis of variance was done followed by the Dunnett's test or the Duncan test. Nociceptive, chimney and traction experiments were analyzed using the Mann and Whitney test. The 5\% level of statistical significance was chosen a priori.

\section{RESULTS}

Targeted disruption of the CCK2 receptor gene did not impair the fertility of mutant mice, and their growth evaluated by body weight was the same as that of wild type mice. Any obvious abnormality in their general appearance relating to the wild type was looked for. The size and histology (Nissl-stained section of hind- 
brain and forebrain) of the brain did not reveal any obvious abnormality (data not shown) as expected from Nagata et al. (1996). The mice studied did not seem sick or injured by fighting with congeners.

The same number of males and females was tested in each experiment and in each strain. There was no significant difference between male and female behaviors in all the experiments except in the open-field test.

Traction, chimney and rotarod tests allow rodents' motor abilities to be examined. CD1 mice were used in these tests to control their performances as compared to those of wild-type (129sv/C57B / 6) mice, used for CCK2 receptor gene invalidation.

\section{Traction Test}

The traction test brings more precisely into play equilibration muscle strength and tonus.

Both CD1 and wild-type (129sv/C57B/6) mice grasped the bar with at least one hind paw in less than 5 s. There is no significant difference between these two strains of mice in this test $(\mathrm{CD} 1=100 \%, \mathrm{WT}=95 \pm 5 \%)$.

CCK2 receptor-deficient $(129 \mathrm{sv} / \mathrm{C} 57 \mathrm{~B} / 6)$ mice did not grasp the bar with at least one hind paw in less than $5 \mathrm{~s}$, showing a significant impairment of performance in the traction test $(20 \%$ of the control) $(\mathrm{U}=125, p<.01)$, Figure 1. This impairment is reproducible since the same results were obtained using four other batches of mice (not shown).

I.p. administration of the selective L365,260 CCKB antagonist at the dose of $200 \mu \mathrm{g} / \mathrm{kg} 45 \mathrm{~min}$ before the test did not change the performance of wild-type mice and CCK2 receptor-deficient mice (Figure 2) (genotype control: $U=21$, genotype L365,260: $U=20, p<.01$ ). The dose of $200 \mu \mathrm{g} / \mathrm{kg}$ of L365,260 used was sufficient to suppress the effects of various behavioral changes induced by CCK2 agonists (Derrien et al. 1993; Smadja et al. 1995; Ladurelle et al. 1997). In addition, we tested $1000 \mu \mathrm{g} / \mathrm{kg}$ in both strains and did not find any difference in relation to $200 \mu \mathrm{g} / \mathrm{kg}$ (not shown).

Therefore, these results show that the blockade of CCK2 receptors by the L365,260 antagonist in wild-type mice did not reproduce the effects obtained in their absence in CCK2 receptor-deficient mice.

\section{Chimney Test}

The chimney test brings into play equilibration muscle strength, tonus and coordination of movements.

Both wild-type and CCK2 receptor-deficient mice climbed back up, upside down, the length of a vertical glass tube in less than $30 \mathrm{~s}$. There is no significant difference between wild-type and CCK2 receptor-deficient mice in the chimney test $(\mathrm{U}=540, \mathrm{NS})$ (not shown).

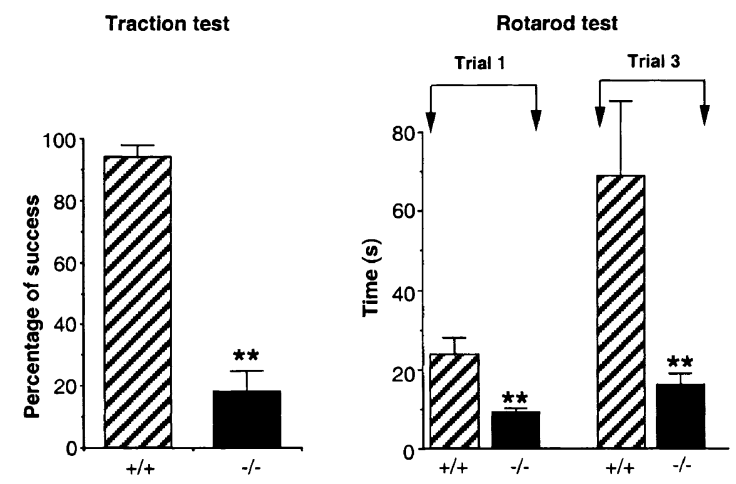

Figure 1. Behavioral analysis of wild-type $(+/+)$ and CCK2 receptor-deficient $(-/-)$ mice in the traction and rotarod tests. Mice were tested for three consecutive trials on the rotarod; the first and third are shown. Results are expressed as the percentage of mice which successfully performed traction and as the time spent (in seconds) on the rotarod. ${ }^{* *} p<.01$ vs. $+/+$ mice, Dunnett's test.

\section{Rotarod Test}

The ability to balance and walk on a rotating cylinder is a test of coordinated motor functions. It can be noticed that in this test, CCK2 receptor-deficient and wild-type mice performed very poorly on the rotarod test during the first trial. This was already reported for wild type 129s/C57B/ 6 mice (Kelly et al. 1998) and also observed in this study for CD1 mice $(\mathrm{CD} 1=36.1 \pm 8.3 \mathrm{~s}$, WT $=$ $23.1 \pm 6.7 \mathrm{~s}, p=.22)$. However, in the third trial, CD1 as well as wild-type mice exhibited an increased score in comparison to the first trial $(\mathrm{CD} 1=65.6 \pm 10.6 \mathrm{~s}, \mathrm{WT}=$ $68.3 \pm 10.1 \mathrm{~s})$.
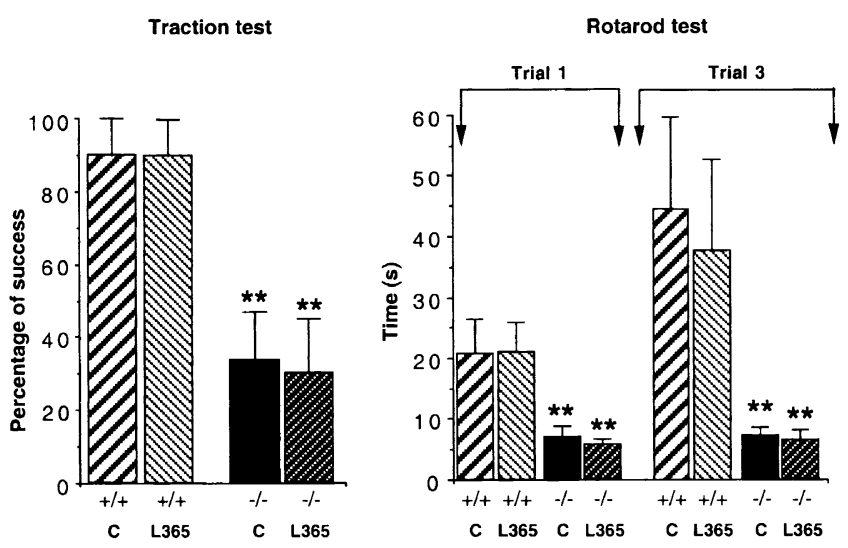

Figure 2. Effects of the selective L365,260 CCK2 antagonist in wild-type $(+/+)$ and CCK2 receptor-deficient $(-/-)$ mice in the traction and rotarod tests. Mice were tested for three consecutive trials in the rotarod; the first and third are shown. L365,260 was i.p. injected at the dose of $200 \mu \mathrm{g} / \mathrm{kg}$, 45 minutes before the tests. Results are expressed as the percentage of mice which succesfully performed traction, and as the time spent (in seconds) on the rotarod. ${ }^{* *} p<.01$ vs. $+/+$ mice, Duncan test. 
Regarding CCK2 receptor-deficient mice, it is interesting to observe that they scored significantly lower than wild-type mice both in the first and the third trials (first trial: $\mathrm{F}(1,65)=12.852, p<.001$; third trial: $\mathrm{F}(1,65)=$ 7.766, $p<.001)$. Moreover, in contrast to wild type 129s/C57B/6 and CD1 mice, CCK2 receptor-deficient mice did not improve their performances on the third trial (Figure 1). This impairment is reproducible since the same results were obtained using four different batches of mice (not shown).

I.p. administration of the selective L365,260 CCKB antagonist at the dose of $200 \mu \mathrm{g} / \mathrm{kg} 45 \mathrm{~min}$ before the test, did not change the performance of wild-type and CCK2 receptor-deficient mice (ANOVA first trial: genotype: $\mathrm{F}(1,36)=6.84, p=.01$, treatment: $\mathrm{F}(1,36)=0.204, p=.60$, interaction: $\mathrm{F}(1,36)=0.198, p=.66$, third trial: genotype : $\mathrm{F}(1,36)=9.538, p<.001$, treatment: $\mathrm{F}(1,36)=0.264, p=$ .61 , interaction: $\mathrm{F}(1,36)=0.195, p=.66$ ) (Figure 2).

\section{Motor Activity Measured in Actimeter}

An increase in motor activity measured in actimeter for 60 min was observed in CCK2 receptor-deficient mice in comparison to wild-type mice. Hyperactivity is observed at $20 \mathrm{~min}(p<.03), 30 \mathrm{~min}(p<.02)$ (Figure 3, Panel A).

On the other hand, i.p. administration of BC264 at the dose of $3 \mu \mathrm{g} / \mathrm{kg}$ induced an increase in the motor activity of wild-type mice (Genotype: $\mathrm{F}(1,46)=6.85 p=.01$, treatment: $\mathrm{F}(3,46)=4.27, p=.01)$, (Figure 3, Panel B).

\section{Locomotor/exploratory Activity Measured in the Open-field Test}

There is no significant difference between wild-type and CCK2 receptor-deficient mice in the number of squares crossed, rearings (Table 1), groomings, latency time and in the number of defecations measured for 6 min in the open-field test (not shown). However, the ANOVA analysis revealed significant differences between males and females in the number of squares crossed $(\mathrm{F}(3,37)=3.315, p=.03)$ and in the number of rearings $(\mathrm{F}(3,37)=4.446, p=.009)$ of both wild type and CCK2 receptor-deficient mice. Females $(+/+$ and $-/-$ ) showed an increase in locomotor activity in comparison to males $(+/+$ and $-/-)$.

\section{Anxiety-related Behavior Measured in the Elevated Plus Maze}

The total number of arm visits, the number and the time spent in closed arms were significantly increased in CCK2 receptor-deficient mice compared to wild-type animals. However there is no significant difference between wild-type and CCK2 receptor-deficient mice in the percentage of visits and of time spent in the maze open arms (measure of anxious reactivity). (Table 2).
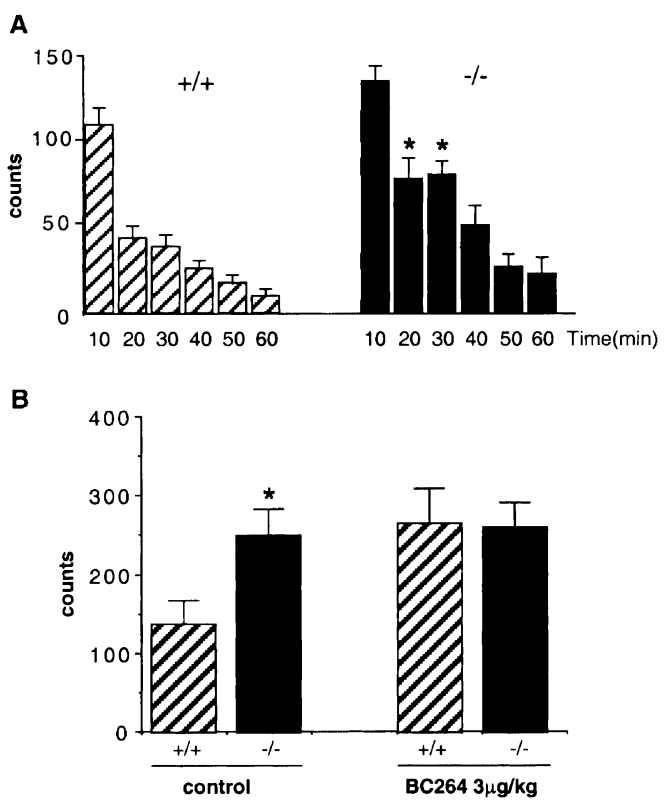

Figure 3. Panel A: Time course of motor activity measured in actimeter for one hour of wild-type $(+/+)$ and CCK2 receptor-deficient $(-/-)$ mice. ${ }^{*} p<.05$ vs. wild-type mice for the same time. Panel B: Measurement of locomotor activity in actimeter for one hour of wild-type $(+/+)$ and CCK2 receptor-deficient $(-/-)$ mice after BC264 i.p. injection at the dose of $3 \mu \mathrm{g} / \mathrm{kg} 30$ minutes before the test. Results are expressed as number of counts. ${ }^{*} p<.05$ vs. control $+/+$ mice, Duncan test.

\section{Conditioned Suppression of Motility Test}

A statistical difference in motor activity was observed between conditioned mice $(C)$ compared to non-conditioned mice (NC) in wild-type or CCK2 receptor-deficient groups, but not between wild-type $(+/+)$ and CCK2 receptor-deficient mice $(-/-)$ in conditioned or non-conditioned mice (number of squares crossed plus rearings: + / + group: $\mathrm{NC}=70.1 \pm 7.8, \mathrm{C}=5.5 \pm 1.6$; $-/-$ group: $\mathrm{NC}=85,6 \pm 6.4, \mathrm{C}=10.0 \pm 2.3)$. ANOVA $=$ genotype factor $=\mathrm{F}(1,38)=1.278, p=.26$; $\mathrm{NC} / \mathrm{C}$ factor $=$ $(1,38)=37.854, p<.001$; interaction $=\mathrm{F}(1,38)=0.224$, $p=.63$ (not shown).

\section{Spontaneous Alternation Behavior Measured in the Y Maze}

There are no significant differences between wild type and CCK2 receptor-deficient mice in the total number of arm visits (+/+: $45.5 \pm 2.3,-/-: 41.6 \pm 2.0$, ANOVA: $\mathrm{F}(1,40)=1.735, p=.1952)$. However a significant decrease in the percentage of spontaneous alternation was observed in the CCK2 receptor-deficient group of mice in comparison to wild-type mice. ANOVA $(\mathrm{F}(1,40)=16.528, p=.0002)$ (Figure 4). 
Table 1. Behavioral Analysis of CCK2 Receptor-Deficient $(-/-, \mathrm{n}=22)$ and Wild-Type $(+/+, \mathrm{n}=19)$ Mice in the Open-Field Test Measured for 6 Min

\begin{tabular}{lcc}
\hline Mice & Squares crossed & Rearings \\
\hline$+/+$ & $236.5 \pm 10.3$ & $21.2 \pm 2.3$ \\
$-/-$ & $228.4 \pm 8.8$ & $23.3 \pm 2.5$ \\
$\mathrm{~F}(1,39)$ & $0.359, \mathrm{P}=0.552$ & $0.395, \mathrm{P}=0.533$ \\
\hline
\end{tabular}

\section{Nociceptive Experiments}

There is no significant difference between wild type and CCK2 receptor-deficient mice in response thresholds towards nociceptive stimuli generated by an electrical stimulation. A footshock of $0.72 \mathrm{~mA}$ induced flinching and/or running in $70 \%$ of CCK2 receptor-deficient mice $(\mathrm{n}=10)$ and in $50 \%$ of wild type mice $(\mathrm{n}=8)(\mathrm{U}=32$, NS), jumping and vocalization in $20 \%$ of CCK2 receptordeficient mice and in $29 \%$ of wild type mice ( $\mathrm{U}=33, \mathrm{NS})$. A footshock of 0.84, 0.96, 1.08 and $1.2 \mathrm{~mA}$ produced jumping and/or vocalization in $100 \%$ of CCK2 receptordeficient mice and in $100 \%$ of wild type mice.

\section{DISCUSSION}

The aim of this study was to investigate the physiological role of the CCK2 receptor in behavioral control by using mice invalidated for this receptor. The responses obtained could be interpreted: (a) by the suppression of endogenous CCK effects acting on CCK2 receptors, (b) by CCK stimulation on the remaining CCK1 receptors or (c) by compensatory processes. Indeed, knockout mice gained the defect at the early phase of embryogenesis and some other genes may compensate, during development, for the deleted one (reviewed in Gerlai 1996). Studies with deficient mice could therefore give insights on the occurrence of compensatory processes due to receptor inactivation.

CCK2 receptor-deficient mice showed a neurologi$\mathrm{cal} /$ muscular impairment as measured in the traction and rotarod tests. In the traction test, which brings into play equilibration muscle strength and tonus, CCK2 re- ceptor-deficient mice did not satisfy the test. As reported by Kelly et al. 1998, wild-type (129sv/C57B/6) but also CD1 mice (see this study) performed poorly on the rotarod test but improved their scores over the three consecutive trials. As shown here, CCK2 receptor invalidation led to an additional reduction in the performances of CCK2 receptor-deficient mice as compared to wild-type animals. Furthermore, there was no improvement observed over the three consecutive trials with the mutants. This could indicate that mice undergo a functional impairment in equilibration muscle strength and tonus and/or in coordinated skills which does not occur when guide constraints exist as in the chimney test. In addition, this latter test also brings into play curiosity, fear and the escape instinct which could explain the lack of impairment in performance of CCK2 receptor-deficient mice in these conditions.

To the best of our knowledge, there is no pharmacological data reporting neurological/muscular impairment following treatments with CCK compounds. Furthermore, acute injection of the L365,260 CCK2 antagonist at the dose suppressing the effects of CCK2 receptor stimulation did not produce any behavioral modification of wild-type mice, indicating that CCK2 receptors were not essential for performing correctly the tasks required in the traction and rotarod tests. In addition, there is no data in the literature indicating that the long term blockade of the CCK2 receptor by selective antagonists affects neuromuscular functions. This suggests that the neuro-muscular impairment of CCK2 receptor-deficient mice is very likely not specifically linked to the CCK2 gene deletion and that other processes such as a polymorphism in the genetic background (reviewed in Gerlai 1996) could be responsible for this effect. However this hypothesis is not supported by the similar impairments obtained with four different batches of mice. On the other hand, the general health of CCK2 receptor-deficient mice appears good and they are not affected by an injured housing environment. Taken together, these results seem to indicate that the impairment observed in the traction and rotarod tests, is the consequence of CCK2 gene deletion, an assumption reinforced by recent data showing a decrease in CCK expression in rat spinal motoneurons chemodenervated

Table 2. Behavioral Analysis of CCK2 Receptor-Deficient $(-/-, \mathrm{n}=9)$ and Wild-Type $(+/+, \mathrm{n}=10)$ Mice in the Elevated Plus Maze Test Measured for 5 Min

\begin{tabular}{lccccccc}
\hline Mice & Total number & OA number & OA time & CA number & CA time & \%OA number & \%OA time \\
\hline$+/+$ & 11.3 & 0.4 & 2.5 & 10.9 & 186.8 & 3.4 & 1.2 \\
& $( \pm 0.9)$ & $( \pm 0.3)$ & $( \pm 1.7)$ & $( \pm 0.9)$ & $( \pm 7.8)$ & $( \pm 2.6)$ & $( \pm 0.8)$ \\
$-/-$ & 13.5 & 1.0 & 4.7 & 12.5 & 197.1 & 5.2 & $( \pm 2.3$ \\
& $( \pm 1.1)$ & $( \pm 0.5)$ & $( \pm 2.6)$ & $( \pm 0.7)$ & $( \pm 6.2)$ & 0.59 & 0.118 \\
$\mathrm{~F}(1,18)$ & 1.023 & 0.378 & 0.377 & 5.108 & 0.453 & 0.732 \\
$p=$ & 0.325 & 0.541 & 0.541 & 0.027 & 0.638 \\
\hline
\end{tabular}

$\mathrm{OA}=$ open arms visits, $\mathrm{CA}=$ closed arms visits. Total number $=$ total number of open and closed arm visits. 


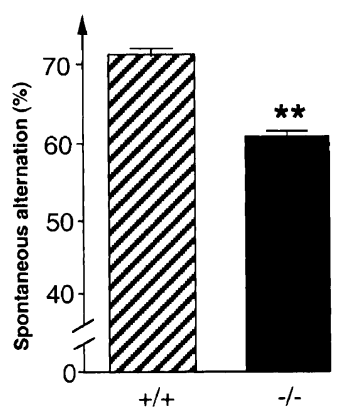

Figure 4. Measurement of spontaneous alternation behavior of wild-type $(+/+)$ and CCK2 receptor-deficient $(-/-)$ mice in a $Y$ maze for 10 minutes. The results are expressed in percentage of spontaneous alternations. ${ }^{* *} p>.01 \mathrm{vs} .+/+$, mice, Dunnett's test.

with the botulinum toxin (Jung et al. 1997). Although CCK binding sites development takes place in rat brain, in most but not all parts of CNS, essentially during the post-natal period, maximal CCK binding is already present at birth in some rat brain structures (endopyriform nucleus, ventromedial hypothalamus nucleus and medial nucleus of amygdala) indicating that CCKergic systems could play a role in the development and maturation of structures of the central nervous system (Pélaprat et al. 1988). Moreover, mice contain CCK2 receptors in the cerebellum but not in the caudate-putamen nucleus (Sekiguchi and Moroji 1986). Regarding the role of the cerebellum in motor coordination, the cause of impairment observed in CCK2 receptor-deficient mice needs further experiments for its elucidation.

It could be argued that the observed impairment in motor function could bias testing and analysis of other behaviors. However, the neuro-muscular impairment of CCK2 receptor-deficient mice is only partial as they performed well in the chimney test. Accordingly, muscular impairment could not explain the behavioral modifications discussed below since differences between both types of mice occur in some tests (actimeter, elevated plus maze) but not in open-field and Y maze, although each assay requires horizontal locomotor activity. In addition, if the impairment had interfered with locomotor activity, the consequence would have been a decrease and not an increase in motor behavior as observed here.

Locomotor activity and exploratory behavior of CCK2 receptor-deficient mice were measured in various situations since the responses obtained with CCK compounds were shown to be dependent on the environment (Daugé et al. 1989; Ladurelle et al. 1995; Ladurelle et al. 1997; see also: reviews in Harro et al. 1993; Crawley and Corwin 1994).

Thus, the spontaneous alternation behavior measured in a Y maze represents a potentially useful tool for investigating attention and/or memory functions (Anisman and Kokkinidis 1975). Mice lacking CCK2 receptors showed a decrease in alternation in comparison to wild-type animals. Since there is no difference in the total number of arm visits between both groups, this suggests an impairment of attention and/or memory processes following receptor disruption. This is in agreement with the impairment in retention of spatial recognition observed with CCK2 receptor-deficient mice using a 2-trial memory test (Sebret et al. 1999).

Locomotor activity measured for $6 \mathrm{~min}$ in the slightly stressful environment of the open-field was not different between wild-type and CCK2 receptor-deficient mice. No difference was also observed in the motor activity of both groups of mice during the first 10 min after the animals were placed in the actimeter for a test. However, following this initial period, CCK2 receptor-deficient mice showed a significant hyperlocomotor activity. In addition the activity of CCK2 receptor-deficient mice decreased less rapidly over time relating to wild-type mice, suggesting an impairment in environmental habituation related to the absence of CCK2 receptors. This is an unexpected result since CCK2 agonists induced an increase, and CCK1 agonists a decrease, in the locomotor activity of mice as measured in the same test (reviewed in Crawley and Corwin 1994; Daugé et al. 1995 and Fig. 3, panel B). The lack of habituation of CCK2 receptor-deficient mice could also explain the decrease of spontaneous alternation behavior and could correspond to a cognitive deficit in these animals (see above).

In addition, when mice were tested in more stressful environments, i.e., the elevated plus maze test (animal model of anxiety) and the motility conditioned suppression test (animal model of depression), there was no difference in measured emotional responses between CCK2 receptor-deficient and wild-type mice. These results appear striking since CCK2 receptors activation (especially the CCK2a subtype) by CCK agonists has been shown to be involved in stress-related behaviors leading to anxiogenic-like responses in mice (Harro et al. 1993; Daugé and Roques 1995). In addition, most of the studies have shown that the blockade of CCK2 receptors by selective antagonists induces anxiolytic-like responses in rodents (Rataud et al. 1991; Singh et al. 1991; Derrien et al. 1994; see also reviews in Harro et al. 1993; Shlik et al. 1997; Daugé and Léna 1998). Therefore, the lack of behavioral modifications observed with CCK2 receptor-deficient mice, could be related to unknown compensatory processes.

Concerning the motility conditioned suppression test, CCK2 agonists were shown to potentiate the reduction in mice motility submitted to the unescapable footshocks. CCK2 antagonists alone did not change the motility of conditioned mice but potentiated the reduction of the conditioned suppression of motility produced by endogenous enkephalins protected from metabolizing 
enzymes by the RB101 dual inhibitor (Smadja et al. 1995). Therefore, the lack of CCK2 receptors is expected to reduce the conditioned suppression of motility or to result in the absence of change in the behavior of mice. The motility conditioned suppression test requires sensitivity to shocks and intact memory performances. The lack of changes between both groups of mice observed in this study can neither be explained by a modification of pain sensitivity since the responses to footshocks were found identical in CCK2 receptor-deficient and wild type mice, nor by a decrease in memory since CCK2 receptor-deficient mice behaved like wild type mice in the motility conditioned suppression test. Together, these results could mean that this stressful situation does not require a phasic release of endogenous CCK or that compensatory processes occur.

In conclusion, some results observed with CCK2 receptor-deficient mice are unexpected. This is the case for the neuromuscular impairment of CCK2 receptordeficient mice which could be due to a polymorphism in the genetic background. However, a role for the CCK2 receptor in this function cannot be excluded as illustrated by the reduction in preproCCKRN during evoked impairment of muscle function after the administration of neurotoxins (Jung et al. 1997). Other results very likely imply the occurrence of compensatory mechanisms, as previously shown with genetically modified animals (Mogil and Grisel 1998). This brings some support to the concept of a modulatory role of peptides in behavioral functions, such as stressful-related behaviors, suggesting that some functionally related neurotransmitter systems could play a compensatory role in CCK2 receptor-deficient mice. On the other hand, other behavioral modifications observed in mutant mice are in agreement with the role of CCK2 receptors. This is the case for the impairment of spontaneous alternation behavior in CCK2 receptor-deficient mice which is in line with the impairment in spatial recognition retention observed in these animals (Sebret et al. 1999). Together, this emphasizes the physiological role of CCK in improving, through CCK2 receptor stimulation, some attention and/or memory processes.

\section{ACKNOWLEDGMENTS}

We thank H. Dhôtel for the synthesis of BC264.

\section{REFERENCES}

Anisman H, Kokkinidis L (1975): Effects of scopolamine, D-amphetamine and other drugs affecting catecholamines on spontaneous alternation and locomotor activity in mice. Psychopharmacologia 45:55-63

Bock MG, Dipardo RM, Evans BE, Rittle KE,Whitter WL,
Veber DF, Anderson PS, Freidinger RM (1989): Benzodiazepine gastrin and brain cholecystokinin receptor ligands : L365,260. J Med Chem 32:13-16

Boissier JR, Tardy J, Diverres JC (1960): Une nouvelle méthode simple pour explorer l'action "tranquillisante": le test de la cheminée. Med Experimentalis 3:81-84

Charpentier B, Durieux C, Pélaprat D, Dor A, Reibaud M, Blanchard J-C, Roques BP (1988): Enzyme-resistant CCK analogues with high selectivity for central receptors. Peptides 9:835-841

Courvoisier S (1956): Pharmacodynamic basis for the use of chlorpromazine in psychiatry. J Clin Exp Psychopath 17:25-37

Crawley JN, Corwin RL (1994): Biological actions of cholecystokinin. Peptides 15:731-755

Crawley JN (1999): Behavioral phenotyping of transgenic and knockout mice: experimental design and evaluation of general health, sensory functions, motor abilities, and specific behavioral tests. Brain Res 835:18-26

Daugé V, Dor A, Féger J, Roques BP (1989): The behavioral effects of the CCK8 injected into the medial nucleus accumbens are dependent on the motivational states of the rats. Eur J Pharmacol 163:25-32

Daugé V, Roques BP (1995): Reward and anxiety: The opposite pharmacology of opioids and CCK. In Bradwejn J, Vasar E (eds), Cholecystokinin and Anxiety, from Neuron to Behavior. Georgetown, Texas, RG Landes Company, pp 161-171

Daugé V, Corringer P-J, Roques BP (1995): CCKA, but not CCKB agonists suppress the hyperlocomotion induced by endogenous enkephalins, protected from enzymatic degradation by systemic RB101. Pharmacol Biochem Behav 50:133-139

Daugé V, Léna I (1998): CCK in anxiety and cognitive processes. Neurosci Biobehav Rev 22:815-825

Derrien M, Noble F, Maldonado R, Roques BP (1993): CCKA or $\mathrm{CCKB}$ receptors activation lead to antinociception and to hyperalgesia respectively: evidence for an indirect interaction with the opioidergic system. Neurosci Lett 160:193-196

Derrien M, McCort-Tranchepain I, Ducos B, Roques BP Durieux C (1994): Heterogeneity of CCKB receptors involved in animal models of anxiety. Pharmacol Biochem Behav 49:133-141

Dockray GJ (1976): Immunochemical evidence of cholecystokinin-like peptides in brain. Nature 264:568-570

Dunham NW, Miya TS (1957): Note on a simple apparatus for detecting neurological deficit in rats and mice. J Am Pharm Ass 46:208-214

Durieux C, Coppey M, Zajac JM, Roques BP (1986): Occurrence of two cholecystokinin binding sites in guinea pig brain cortex. Biochem Biophy Res Commun 137:1167-1173

Gaudreau P, Quirion R, Saint-Pierre S, Pert CB (1983): Characterization and visualization of cholecystokinin receptors in the rat brain using $(3 \mathrm{H})$-pentagastrin. Peptides $4: 755-762$

Gerlai R (1996): Gene-targeting studies of mammalian behavior: is it the mutation or the background genotype. TINS 19:177-182

Harper EA, Shankley NP, Black JW (1999a): Characteriza- 
tion of the binding of a novel radioligand to CCKB/gastrin receptors in membranes from rat cerebral cortex. Brit J Pharmacol 126:1504-1512

Harper EA, Griffin EP, Shankley NP, Black JW (1999b): Analysis of the behaviour of selected CCKB/gastrin receptor antagonists in radioligand binding assays performed in mouse and rat cerebral cortex. Brit J Pharmacol 126:1496-1503

Harro J, Vasar E, Bradwejn J (1993): CCK in animal and human, research on anxiety. Trends Pharmacol Sci 14: 244-249

Hill DR, Campbell NJ, Shaw TM, Woodruff GM (1987): Autoradiographic localization and biochemical characterization of peripheral type CCK receptors in rat CNS using highly selective nonpeptide CCK antagonists. J Neurosci 7:2967-2976

Jung HH, Lauterbur TH, Burgunder JM (1997): Expression of neurotransmitter genes in rat spinal motoneurons after chemodenervation with botulinum toxin. Neuroscience 78:469-479

Kameyama T, Nagasaka M (1982): Effects of apomorphine and diazepam on a quickly learned conditioned suppression in rats. Pharmacol Biochem Behav 17:59-63

Kelly MA, Rubinstein M, Phillips TJ, Lessov CN, BurkhartKasch S, Zhang GE, Bunzow JR, Fang Y, Gerhardt GA, Grandy DK, Low MJ (1998): Locomotor activity in D2 dopamine receptor-deficient mice is determined by gene dosage, genetic background, and developmental adaptations. J Neurosci 18:3470-3479

Kieffer B (1999): Opioids: first lessons from knockout mice. TiPS 20:19-25

Ladurelle N, Roques BP, Daugé V (1995): The transfer of rats from a familiar to a novel environment prolongs the increase of extracellular dopamine efflux induced by CCK8 in the posterior nucleus accumbens. J Neurosci 15:3118-3127

Ladurelle N, Keller G, Blommaert A, Roques BP, Daugé V (1997): The CCKB agonist, BC264, increases dopamine in the nucleus accumbens and facilitates motivation and attention after intraperitoneal injection in rats. Eur J Neurosci 9:1804-1814

Lee YM, Beinborn M, McBride EW, Lu M, Kolakowski LF, Kopin Jr AS (1993): The human brain cholecystokininB/gastrin receptor. J Biol Chem 268:8164-8169

Léna I, Simon H, Roques BP, Daugé V (1999): Opposing effects of two CCKB agonists on the retrieval phase of a two-trial recognition task after systemic injection in the rat. Neuropharmacol 38:543-553

Miyasaka K, Shinozaki H, Suzuki S, Sato Y, Kanai S, Masuda M, Jimi A, Nagata A, Matsui T, Noda A, Kono A, Funakoshi A (1999): Disruption of cholecystokinin (CCK)-B receptor gene did not modify bile or pancreatic secretion or pancreatic growth: A study in CCKB receptor gene knockout mice. Pancreas 19:114-118

Mogil T, Grisel JL (1998): Transgenic studies of pain. Pain 77: $107-128$

Moran TH, Robinson PH, Goldrich MS, McHungh PR (1986): Two brain cholecystokinin receptors: Implications for behavioral actions. Brain Res 362:175-179
Nagata A, Mitsuhiro I, Iwata N, Kuno J, Takano H, Miniwa O, Chihara K, Matsui T, Noda T (1996): G protein-coupled cholecystokinin-B/gastrin receptors are responsible for physiological cell growth of the stomach mucosa in vivo. Proc Natl Acad Sci USA 93:11825-11830

Noble F, Stephen AW, Crawley JN, Bradwejn J, Seroogy KB, Hamon M, Roques BP (1999): International Union of Pharmacology. XXI. Structure, Distribution, and Functions of Cholecystokinin Receptors. Pharmacol Rev 51:745-781

Pélaprat D, Broer Y, Studler JM, Peschanski M, Tassin JP, Glowinski J, Rostenes W, Roques BP (1987): Autoradiography of CCK receptors in the rat brain using $(3 \mathrm{H})$ Boc(Nle $\left.{ }^{28,31}\right) \mathrm{CCK}_{27-33}$ and $\left({ }^{125} \mathrm{I}\right)$ Bolton-Hunter CCK8. Functional significance of subregional distributions. Neurochem Int 10:495-508

Pélaprat D, Dusart I, Peschanski M (1988): Postnatal development of cholecystokinin (CCK) binding sites in the rat forebrain and midbrain: an autoradiographic study. Developmental Brain Res 44:119-132

Pellow S, Chopin P, File SE, Briley M (1985): Validation of open/closed arm entries in an elevated plus-maze as a measure of anxiety in the rat. J Neurosci Methods 14: 149-167

Pommier B, Da Nascimento S, Dumont S, Bellier B, Million E, Garbay C, Roques BP, Noble F (1999): The cholecystokinin $\mathrm{B}$ receptor is coupled to two effector pathways through pertussis toxin-sensitive and -insensitive $G$ proteins. J Neurochem 73: 281-288

Rataud J, Darche F, Piot O, Stutzmann JM, Böhme GA, Blanchard JC (1991): Anxiolytic effect of CCK-antagonists on plus-maze behavior in mice. Brain Res 548: 315-317

Sebret A, Léna I, Crété D, Matsui T, Roques BP, Daugé V (1999): Rat hippocampal neurons are critically involved in physiological improvement of memory processes induced by cholecystokinin-B receptor stimulation. J Neurosci 15:7230-7237

Sekiguchi R, Moroji T (1986): A comparative study on characterization and distribution of cholecystokinin binding sites among the rat, mouse and guinea-pig brain. Brain Res 399:271-281

Shlik J, Vasar E, Bradwejn J (1997): Cholecystokinin and psychiatric disorders. CNS Drugs 8:134-152

Singh L, Field MJ, Hughes J, Menzies R, Oles RJ, Vass CA, Woodruff GN (1991): The behavioral properties of CI988, a selective cholecystokinin B receptor antagonist. Brit J Pharmacol 104:239-245

Smadja C, Maldonado R, Turcaud S, Fournié-Zaluski MC, Roques BP (1995): Opposite role of CCKA and CCKB receptors in the modulation of endogenous enkephalin antidepressant-like effects. Psychopharmacol 120:400-408

Vanderhaeghen JJ (1975): New peptide in the vertebrate CNS reacting with antigastrin antibodies. Nature 257: 604-605

Wank SA, Pisegna JR, De Weerth A (1992): Brain and gastrointestinal cholecystokinin receptor family: Structure and functional expression. Proc Natl Acad Sci USA 89: 8691-8695 